\title{
Molecular imaging for detection of sensitivity and resistance to EGFR tyrosine kinase inhibitors in non-small cell lung cancer
}

\author{
F. Iommelli $\cdot$ V. De Rosa $\cdot$ R. Fonti $\cdot$ \\ S. Del Vecchio
}

Received: 2 October 2013/Accepted: 28 January 2014/Published online: 20 February 2014

(C) Italian Association of Nuclear Medicine and Molecular Imaging 2014

\begin{abstract}
Advancing knowledge of non-small cell lung cancer (NSCLC) has provided new treatment options based on the specific gene alterations found in individual tumors. The presence of activating mutations in the epidermal growth factor receptor (EGFR) in NSCLC is strongly associated with a high sensitivity to EGFR tyrosine kinase inhibitors (TKIs) and is also a criterion used to identify candidates for first-line therapy with these drugs among patients with advanced disease. However, acquired resistance to EGFR TKIs invariably emerges over time due in part to secondary mutations in EGFR or redundant lateral signaling. Molecular imaging, allowing the visualization of cellular processes and their modulation by both conventional anticancer drugs and molecularly targeted agents, may be effectively used in NSCLC patients during treatment with EGFR TKIs. In particular, positron emission tomography with ${ }^{18} \mathrm{~F}$-FDG and ${ }^{18} \mathrm{~F}$-FLT has been performed in both preclinical and clinical settings to distinguish treatment-sensitive from treatment-resistant NSCLCs. Here we provide a short overview of the mechanisms underlying sensitivity and resistance of NSCLCs to EGFR TKIs and then focus on the contribution that molecular imaging can make to the development of tailored therapy in NSCLC patients.
\end{abstract}

Keywords ${ }^{18}$ F-FDG $\cdot{ }^{18}$ F-FLT $\cdot$ EGFR $\cdot$ Lung cancer

Color figures online at http://link.springer.com/article/10.1007/ s40336-014-0050-6

F. Iommelli · V. De Rosa · R. Fonti - S. Del Vecchio Institute of Biostructures and Bioimages, National Research Council, Naples, Italy

S. Del Vecchio $(\square)$

Department of Advanced Biomedical Sciences, University

"Federico II", Via Pansini 5, Edificio 10, 80131 Naples, Italy

e-mail: delvecc@unina.it

\section{Introduction}

Non-small cell lung cancer (NSCLC) is the leading cause of cancer-related deaths in the world, showing only limited responsiveness to conventional anticancer agents. The development of molecularly targeted agents and, in particular, of small-molecule inhibitors of the epidermal growth factor receptor (EGFR) has provided alternative strategies for treating this disease. However, in initial clinical trials with first-generation EGFR tyrosine kinase inhibitors (TKIs) such as gefitinib and erlotinib, only $10 \%$ of unselected patients with NSCLC were found to respond to treatment [1-4]. In the context of efforts to understand the genetic alterations occurring in highly responsive tumors, subsequent molecular studies identified the presence of activating mutations in EGFR as a major determinant underlying effective tumor response of NSCLC to gefitinib and erlotinib [5-7]. These mutations cause enhanced kinase activity and transformation capability of EGFR, with the result that NSCLC cells become dependent on EGFR signaling for survival [8]. Therefore, when mutant EGFR is blocked by gefitinib or erlotinib, tumor cells undergo apoptosis in addition to growth arrest. Clinical trials in patients with advanced EGFR-mutant NSCLC treated with gefitinib or erlotinib showed that approximately $75 \%$ of patients achieved response and this rate was much higher than that found in unselected patients [9-13]. These clinical studies also showed that EGFR TKIs were superior to chemotherapy as an initial treatment for EGFR-mutant lung cancer, resulting in a three- to fourfold improvement of progression-free and overall survival rates. Furthermore, it should be noted that clinical benefit from treatment with EGFR TKIs is not limited to patients harboring EGFR mutations but may also be observed in patients with EGFR amplification [14] 
and in subgroups of patients with undetectable EGFR mutations [15].

Since approximately $25 \%$ of patients with EGFRmutant tumors do not respond to therapy with EGFR TKIs and not all patients with undetectable EGFR mutations are refractory to therapy, it is clinically relevant to distinguish between sensitive and resistant tumors early in the course of treatment. Furthermore, considering that almost $90 \%$ of unselected patients are non-responders to EGFR TKIs and virtually all EGFR-mutant NSCLC patients who initially respond to therapy will subsequently develop resistance to EGFR inhibitors, early detection of resistance to EGFR TKIs may allow the timely adoption of alternative treatment strategies in refractory patients.

Although drug sensitivity and resistance are two sides of the same coin, they are governed by different mechanisms. We here provide a short overview of the mechanisms underlying sensitivity and resistance of NSCLC to EGFR TKIs and then focus on the contribution that molecular imaging can make to the non-invasive identification of responding and refractory NSCLC patients.

\section{Sensitivity of NSCLC to EGFR TKIs}

EGFR belongs to a family of receptor tyrosine kinases that also includes HER2, HER3 and HER4. EGFR exists as an inactive monomer composed of an extracellular ligandbinding domain, a transmembrane domain and an intracellular tyrosine kinase domain. Upon binding to ligands such as epidermal growth factor and transforming growth factor- $\alpha$, the receptor undergoes conformational changes that allow homodimerization or heterodimerization with other members of the same family [16]. Dimerization of EGFR is followed by autophosphorylation of key tyrosine residues in the tyrosine kinase domain, recruitment of several adapter proteins and initiation of the signaling cascade through several pathways including the Ras/Raf/ MAPK, PI3K/AKT and signal transducers and activators of transcription (STAT) pathways. These signaling events ultimately control multiple cellular processes including proliferation and survival. EGFR TKIs compete with ATP for binding to the catalytic kinase domain of EGFR thus inhibiting ligand-stimulated receptor autophosphorylation.

The majority of activating mutations in EGFR occur within the tyrosine kinase domain [17]. The most common of these are exon 19 deletions that eliminate four amino acids from the tyrosine kinase domain and an exon 21 missense mutation that substitutes arginine for leucine at position 858 (L858R). These mutations were found in $10 \%$ of Caucasian and $30-40 \%$ of Asian NSCLC patients and are associated with an increased sensitivity to EGFR TKIs. They are more frequent in patients with adenocarcinoma, never smokers, females and individuals of East Asian ethnicity, all clinical characteristics previously reported to be present in good responders to EGFR TKIs [14].

Exon 19 deletions and L858R substitutions are referred to as "activating mutations" because they cause a ligandindependent activation of EGFR tyrosine kinase activity, as a result of which the receptor continuously transduces signals inside the cell $[18,19]$. As a consequence, downstream signaling pathways are persistently activated and drive oncogenesis and tumor progression. However, when EGFRmutant NSCLCs are exposed to EGFR inhibitors, signaling through these pathways, being under the exclusive control of EGFR, is suppressed. This will result in growth arrest and in the activation of apoptosis through up-regulation of BIM, a pro-apoptotic member of the Bcl-2 family [20].

The presence of activating mutations in EGFR is currently a criterion used to identify, among NSCLC patients, candidates for first-line therapy with EGFR TKIs.

\section{Primary resistance to EGFR TKIs}

NSCLC patients who, since starting treatment, have never achieved tumor response are considered to have primary resistance to EGFR TKIs. This resistance may be due to different molecular mechanisms (Fig. 1) [18]. The expression of wild-type EGFR is usually associated with primary resistance to EGFR TKIs. The wild-type receptor shows much higher binding affinity for ATP than for gefitinib or erlotinib; therefore, inhibition of receptor autophosphorylation can occur only at high concentrations of the drug, not usually achievable in the plasma of treated patients. More importantly, the expression of wild-type EGFR is, in a considerable percentage of cases, accompanied by mutations in other genes such as KRAS and BRAF. Activating mutations in KRAS are observed in about $25 \%$ of NSCLC cases and occur almost exclusively in patients with EGFR wild-type tumors. Constitutive activation of KRAS results in continuous transduction of signals regulating proliferation, survival and motility inside the cell independently of the activation status of EGFR. Mutations in BRAF that encode for a downstream mediator of EGFR signaling are found in 2-3\% in NSCLCs. BRAF and KRAS mutations are mutually exclusive. The most common mutation of BRAF is V600E and NSCLC cell lines bearing this mutation are resistant to EGFR inhibitors but sensitive to MEK inhibitors [21].

Small insertions or duplications in exon 20 are associated with primary resistance to EGFR TKIs and occur in about $5 \%$ of NSCLC cases [18]. Although rare, they are clinically relevant since most patients with tumors harboring exon 20 insertions show tumor progression despite treatment with EGFR TKIs. 


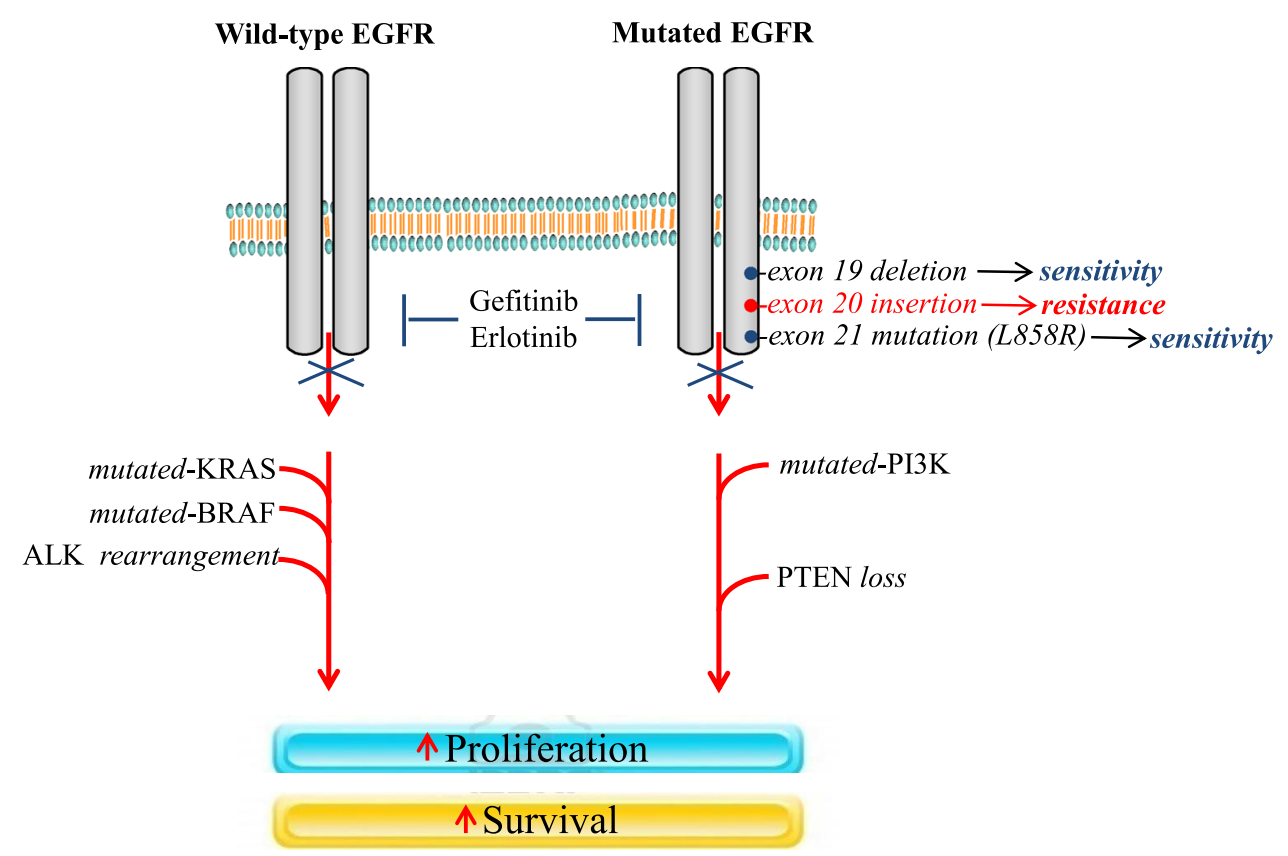

Fig. 1 Primary resistance to EGFR TKIs in NSCLC. A schematic representation of mechanisms underlying primary resistance of NSCLC to EGFR TKIs is shown. The expression of wild-type EGFR is usually associated with primary resistance to EGFR TKIs due to the higher affinity of the receptor for ATP rather than for gefitinib or erlotinib. A considerable percentage of NSCLCs with wild-type EGFR also harbor mutations in the KRAS or BRAF genes, as well as an ALK rearrangement resulting in a persistent activation of EGFR

Almost $5 \%$ of NSCLCs harbor translocations in the anaplastic lymphoma kinase (ALK) gene which lead to transcription of the fusion protein EML4-ALK which comprises the amino-terminal half of echinoderm microtubule-associated protein-like 4 and the intracellular catalytic domain of ALK [22, 23]. The fusion transcript has transforming ability and ALK rearrangement is currently considered the second oncogenic driver in NSCLC after activating EGFR mutations [24]. ALK translocations generally occur in tumors with wild-type EGFR and KRAS. ALK fusion-positive lung tumors are resistant to treatment with EGFR TKIs but sensitive to ALK inhibitors such as crizotinib [25]. Despite the presence of activating mutations, primary resistance to EGFR TKIs can occur due to the presence of concurrent mutations causing gain or loss of function of downstream mediators such as PI3K or PTEN. Although rare, mutations of the catalytic subunit of PI3K and loss of PTEN are both correlated with decreased sensitivity to EGFR TKIs [26, 27].

\section{Acquired resistance to EGFR TKIs}

Acquired resistance to EGFR TKIs occurs in virtually all EGFR-mutant NSCLC patients who initially respond to pathways Despite the presence of activating mutations in EGFR, primary resistance to EGFR TKIs may be due to mutations in catalytic subunits of PI3K or to PTEN loss, both of which keep EGFR pathways persistently activated even in the presence of gefitinib and erlotinib. Among the primary mutations occurring in the tyrosine kinase domain of EGFR, exon 20 insertion confers resistance to EGFR TKIs. All these genetic alterations finally result in enhanced proliferation and survival (color figure online)

therapy. To date, two mechanisms of acquired resistance to EGFR TKIs have been identified in patients with refractory NSCLC (Fig. 2) [19]. Approximately $50 \%$ of resistant tumors harbor a secondary point mutation in the tyrosine kinase domain of EGFR. The threonine-790 to methionine (T790M) mutation confers resistance to EGFR TKIs. The threonine residue is located near the kinase active site and when it is substituted with a bulky methionine the binding of gefitinib or erlotinib to the ATP pocket of EGFR can be altered because of steric hindrance or a reduced binding affinity [19]. The T790M mutation usually occurs in EGFR with activating mutations under the selective pressure of the drug. Therefore, most patients who become refractory after an initial response harbor a double-mutant EGFR. Multiple re-responses to EGFR TKIs after a short period of drug discontinuation have been reported [28]. Serial biopsies revealed that T790M mutation can be lost in the absence of the continued selective pressure of EGFR TKIs [29].

A second known mechanism of acquired resistance to EGFR TKIs is MET oncogene amplification, which is observed in up to $20 \%$ of EGFR-mutant NSCLCs that become resistant to gefitinib or erlotinib [19]. NSCLC cells with MET amplification are able to maintain activation of the PI3K/AKT pathway through HER3 phosphorylation 
Mutated EGFR

(exon 19 deletion or L858R)
Mutated EGFR

(exon 19 deletion or L858R) MET

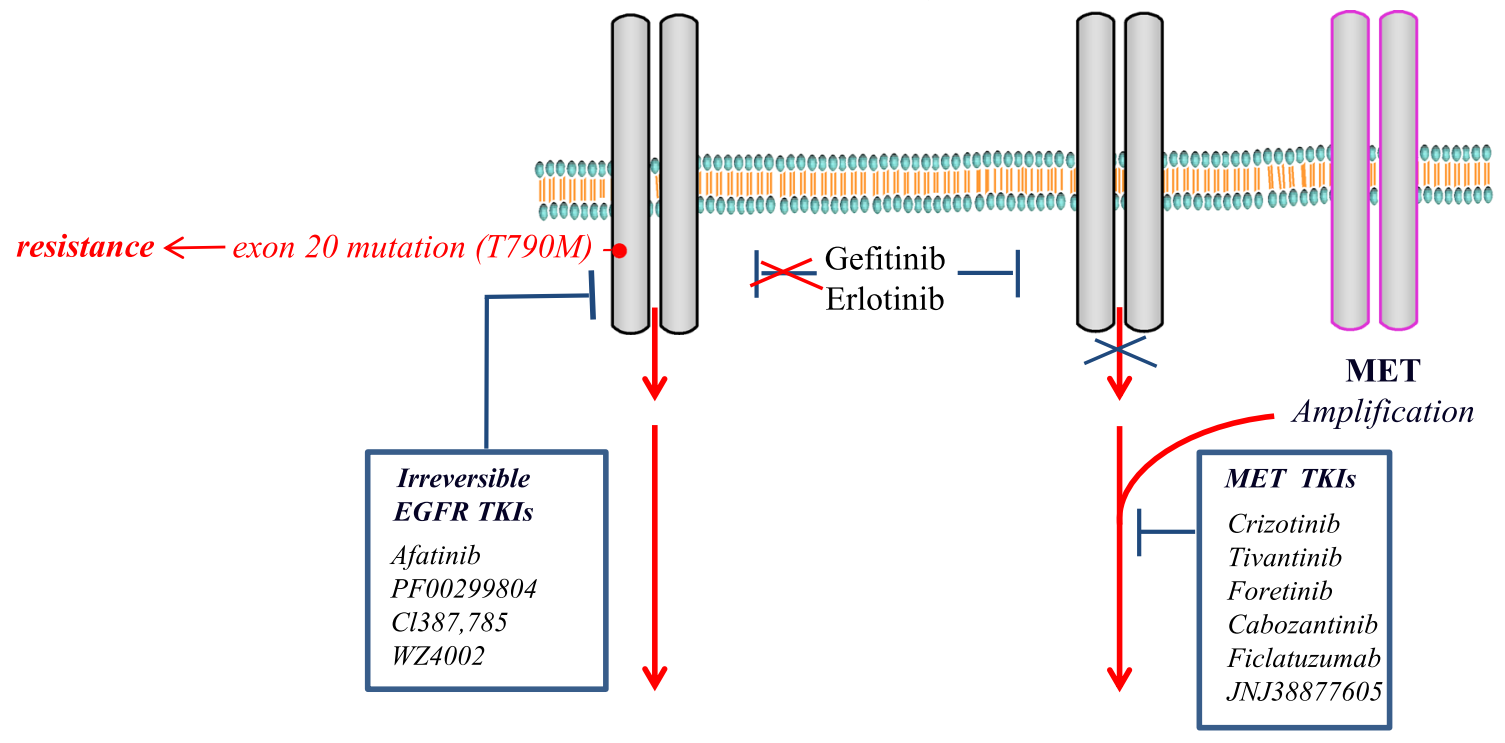

\section{$\uparrow$ Proliferation}

\section{$\uparrow$ Survival}

Fig. 2 Acquired resistance to EGFR TKIs in NSCLCs. A schematic representation of mechanisms underlying acquired resistance of NSCLC to EGFR TKIs is shown. Acquired resistance to EGFR TKIs is mainly due to two mechanisms. Secondary EGFR mutation T790M is found in $50 \%$ of refractory patients who initially respond to EGFR TKIs. The T790M mutation usually occurs in EGFR with activating mutations under the selective pressure of the drug. The second known

despite the inhibition of EGFR by gefitinib or erlotinib. MET is a receptor tyrosine kinase also known as the hepatocyte growth factor (HGF)/scatter factor receptor whose aberrant activation and expression occurs in many types of cancer including NSCLC [30]. Binding of HGF to MET causes receptor dimerization and autophosphorylation of tyrosine residues in the kinase domain, which leads to activation of downstream signaling cascades regulating multiple biological activities such as motility, proliferation, survival and morphogenesis. A major role of sustained MET activation in many types of cancer is to promote cell invasiveness and metastatic spread. MET amplification in NSCLC cells is reported to confer dependence on MET signaling and redundant activation of HER3 for growth and survival.

\section{Reversal of resistance to EGFR TKIs}

Overcoming primary resistance of NSCLC to EGFR TKIs is challenging since it is due to multiple and often rare genetic alterations. Molecular profiling of lung cancer mechanism of acquired resistance is MET amplification which keeps EGFR pathways persistently activated even in the presence of gefitinib and erlotinib. Several compounds (in blue boxes) have been developed that are capable of overcoming T790M-mediated resistance and MET-mediated resistance, thus effectively reducing proliferation and survival (color figure online)

specimens to assay multiple genetic lesions at the same time [31] may, therefore, be necessary to identify the primary cause of the resistance. Despite the fact that implementing these technically demanding procedures in routine clinical practice is difficult, ongoing clinical trials are investigating alternative treatment strategies in subgroups of NSCLC patients. For instance ALK-positive NSCLC patients have been enrolled in several clinical trials testing the activity of crizotinib, a potent ALK and MET inhibitor [25]. Preliminary data showed that treatment with crizotinib results in high response rates and improved progression-free survival as compared to standard chemotherapy [25].

Considerable efforts are currently being made to overcome acquired resistance to EGFR TKIs. NSCLCs that become resistant to gefitinib or erlotinib due to secondary T790M mutation remain dependent on EGFR signaling for growth and survival. Therefore, the development of drugs capable of inhibiting EGFR T790M may constitute an alternative and effective therapeutic strategy in refractory patients. Second- and third-generation EGFR inhibitors were indeed developed in an attempt to overcome T790M- 
mediated resistance [18]. These compounds, like gefitinib and erlotinib, compete with ATP for binding to the kinase domain of EGFR but unlike first-generation agents their binding to the receptor is covalent and irreversible. They were reported to inhibit autophosphorylation of EGFR in the presence of the T790M mutation and showed activity in gefitinib-resistant preclinical models of NSCLC bearing EGFR T790M [32, 33]. However, their clinical efficacy remains to be established in currently ongoing clinical trials. A major concern of early clinical studies has been toxicity, since these compounds can irreversibly block wild-type EGFR too. While most of the second-generation EGFR TKIs recognize receptors bearing activating mutations with a higher affinity than for the double-mutant EGFR, a third-generation EGFR TKI, namely WZ4002, selectively targets T790M-harboring receptors that can be effectively inhibited at doses that will not affect wild-type EGFR thus limiting potential toxicity [34].

In order to overcome MET-mediated resistance to EGFR TKIs, concomitant inhibition of both EGFR and MET is required. Multiple agents have been developed to target MET signaling and they are currently under clinical investigation in different types of solid tumors [30]. Protein-based antagonists of HGF and MET disrupt the binding of HGF to MET and function outside the cells. Conversely, small kinase inhibitors function inside the cell and prevent receptor transactivation and downstream signaling. They constitute the largest class of MET inhibitors currently available and most of them compete with ATP for binding to the kinase domain of MET. Some MET inhibitors are selective for the receptor whereas others have multiple targets. Preclinical studies showed antitumor activity and antiangiogenic activity of MET TKIs in several models and many of these compounds are now in various stages of clinical development.

\section{Molecular imaging with ${ }^{18}$ F-FDG and ${ }^{18}$ F-FLT}

Molecular imaging, allowing the visualization of cellular processes and their modulation by both conventional anticancer drugs and molecularly targeted agents, may be effectively used in NSCLC patients during treatment with EGFR TKIs. In particular, positron emission tomography (PET) with ${ }^{18}$ F-FDG and ${ }^{18}$ F-FLT has been employed in both preclinical and clinical studies to test whether imaging studies performed with these tracers were able to distinguish sensitive from resistant NSCLCs.

The rationale for using ${ }^{18} \mathrm{~F}$-FLT rests on the fact that all signaling pathways downstream of EGFR culminate in proliferation and when they are blocked by targeted therapy, proliferation is inhibited. Given that ${ }^{18}$ F-FLT uptake has been shown to be a sensitive and reliable marker of proliferation in different tumor types including NSCLC [35-37], changes in tracer uptake in response to EGFR TKI treatment may reflect modulation of proliferation.

The uptake of ${ }^{18} \mathrm{~F}$-FDG has been reported to be a reliable predictor of clinical outcome in several types of solid and lymphoproliferative tumors [38-41]. The rationale for using ${ }^{18} \mathrm{~F}-\mathrm{FDG}$ to test inhibition of EGFR pathways is less direct than that supporting the use of ${ }^{18} \mathrm{~F}$-FLT, but nevertheless robust. In fact, one of the major determinants of the glycolytic phenotype of cancer cells is the PI3K/AKT pathway which is persistently activated by aberrant EGFR signaling. Furthermore, downstream effector AKT phosphorylates key glycolytic enzymes such as hexokinase and phosphofructokinase 2 and increases the expression and membrane translocation of glucose transporters [42]. Therefore, EGFR TKIs, by inhibiting pathways downstream of EGFR, including PI3K/AKT, promptly downregulate glycolysis and uptake of ${ }^{18}$ F-FDG. In addition, as a late effect, EGFR TKIs cause a reduction of cell viability and glucose uptake by inducing apoptosis in tumor cells.

In this section we will focus on the use of these tracers to identify sensitivity and resistance of NSCLC to EGFR TKIs through monitoring of treatment with these drugs.

In gefitinib-sensitive NSCLC cells, EGFR inhibition resulted in a rapid reduction in ${ }^{18} \mathrm{~F}$-FDG uptake that correlated with AKT inhibition and preceded any measurable changes in $\mathrm{S}$ phase fraction, thymidine uptake, and annexin $\mathrm{V}$ binding [43]. No significant change in ${ }^{18} \mathrm{~F}-\mathrm{FDG}$ uptake was observed in gefitinib-resistant NSCLC cells, regardless of treatment time or dose. Similarly, ${ }^{18}$ F-FDG uptake decreased by at least $40 \%$ in mice bearing sensitive tumors after only 2 days of treatment, at which time there was no measurable change in tumor size. By contrast no significant decrease in ${ }^{18} \mathrm{~F}$-FDG uptake was observed in mice bearing resistant tumors.

Sunaga et al. [44] evaluated five patients with advanced NSCLC and known EGFR mutational status. They underwent ${ }^{18}$ F-FDG PET before, 2 days after and 4 weeks after gefitinib treatment and tumor response was evaluated using the Response Evaluation Criteria In Solid Tumors (RECIST) after 4 weeks. In patients with partial response or stable disease, ${ }^{18} \mathrm{~F}$-FDG uptake decreased by $61 \pm 18$ and $59 \pm 12 \%$, respectively, at 2 days and by $26 \pm 6$ and $43 \pm 10 \%$ at 4 weeks after the start of therapy. By contrast, increased ${ }^{18} \mathrm{~F}$-FDG uptake was observed in a patient with progression both on the early $(153 \pm 21 \%)$ and the late scan $(232 \pm 73 \%)$.

In a multicenter study, previously untreated patients with operable NSCLC received neoadjuvant treatment with erlotinib and underwent ${ }^{18} \mathrm{~F}$-FDG PET/CT at baseline and 7 days after the initiation of treatment [45]. The European Organisation for Research and Treatment of Cancer (EORTC) criteria were used to assess metabolic tumor 


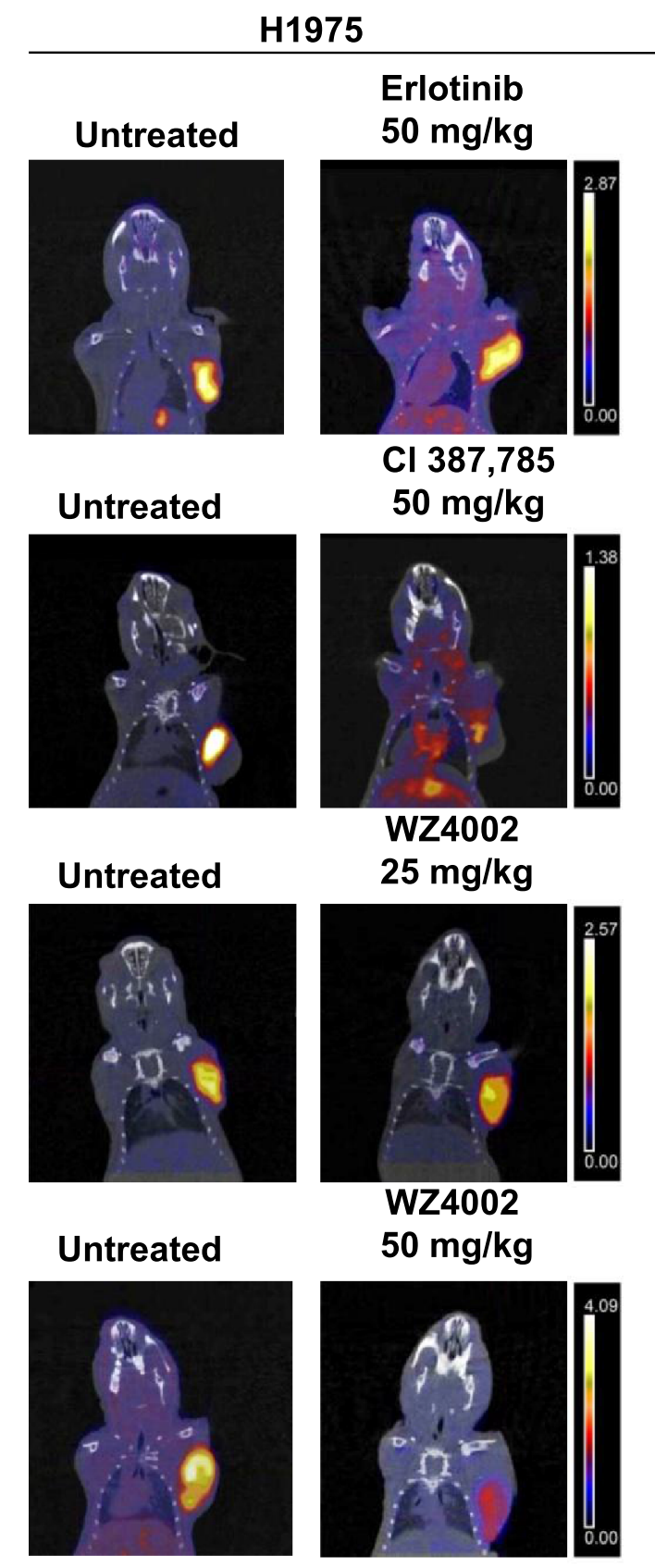

Fig. 3 Coronal fusion images of small-animal PET/CT studies performed with ${ }^{18} \mathrm{~F}$-FLT in nude mice with T790M mutationharboring NSCLCs. The studies were performed before (left) and after (right) treatment with erlotinib and irreversible inhibitors such as CL-387,785 and WZ4002 capable of overcoming T790M-mediated resistance. A dose-dependent reduction in ${ }^{18}$ F-FLT uptake was observed in tumor after treatment with CL-387,785 and WZ4002, whereas erlotinib was ineffective in the same animals. The color scale on the right shows that the same threshold values of SUV were applied to pretreatment and postreatment PET images. (This research was originally published in JNM. Zannetti A, Iommelli F, Speranza A, Salvatore M, Del Vecchio S. $3^{\prime}$-deoxy- $3^{\prime}{ }^{1}{ }^{18}$ F-fluorothymidine PET/ CT to guide therapy with epidermal growth factor receptor antagonists and Bcl-xL inhibitors in non-small cell lung cancer. J Nucl Med 2012 Mar; 53(3):443-50, by the Society of Nuclear Medicine and Molecular Imaging, Inc.) (color figure online) response: six patients showed a partial response, 16 patients had stable disease, and one patient had progressive disease. Pathologic response was determined in surgically resected tumors and the median percentage of necrosis was $70 \%$ in patients showing more than $25 \%$ reduction in ${ }^{18} \mathrm{~F}$ FDG uptake after 1 week of treatment, whereas it was $40 \%$ in the metabolic non-responders (stable disease and progression). Interestingly, of ten patients with unchanged or increased ${ }^{18}$ F-FDG uptake after 1 week of treatment, only one patient showed a pathologic response with more than $50 \%$ necrosis in tumor specimen, indicating that persistently high ${ }^{18} \mathrm{~F}$-FDG uptake after therapy is consistently associated with impaired tumor response.

Ullrich et al. [46] reported a prompt reduction in ${ }^{18} \mathrm{~F}$ FLT uptake in sensitive xenografts and persistently enhanced tracer uptake in resistant tumors after 2-4 days of erlotinib treatment. In another study nude mice bearing sensitive and resistant NSCLC xenografts were studied with ${ }^{18}$ F-FLT before and 2 days after treatment with erlotinib. Sensitive tumors showed a mean decrease in ${ }^{18} \mathrm{~F}$ FLT uptake of $45 \%$, whereas resistant tumors bearing a T790M mutation showed a mean increase in ${ }^{18} \mathrm{~F}$-FLT uptake of $27 \%$. More importantly, treatment of resistant animals with CL-387,785 and WZ4002, two irreversible EGFR TKIs, caused mean decreases in tracer uptake of 21 and $36 \%$, respectively, indicating reversal of T790Mmediated resistance (Fig. 3) [47].

Sohn et al. [48] evaluated 28 patients with recurrent adenocarcinoma of the lung before and 7 days after the start of gefitinib treatment with ${ }^{18}$ F-FLT PET; tumor response was subsequently evaluated by chest CT scan at 6 weeks of therapy. These authors found that percent changes in ${ }^{18}$ F-FLT uptake at 7 days were significantly different in responders $(-36.0 \pm 15.4 \%)$ compared with non-responders $(10.1 \pm 19.5 \%)$, whereas the pretreatment maximum standardized uptake value (SUVmax) of the tumors did not differ in the two groups of patients. Furthermore, the time to progression was significantly longer in ${ }^{18}$ F-FLT PET responders versus non-responders.

In a prospective trial, conducted with the aim of identifying predictors of non-progression following erlotinib treatment, 34 unselected patients with untreated advanced NSCLC underwent ${ }^{18}$ F-FDG PET and ${ }^{18}$ F-FLT PET [49]. EGFR mutational status was determined in 28 of the 34 patients. Changes in ${ }^{18}$ F-FDG and ${ }^{18}$ F-FLT uptake after one and 6 weeks of erlotinib treatment were compared with non-progression measured by CT at 6 weeks. Four patients had a partial response (PR), seven stable disease (SD) and 23 progression, according to RECIST. A reduction of at least $30 \%$ in ${ }^{18}$ F-FDG uptake after 1 week of therapy was observed in eight patients and found to predict non-progression $(\mathrm{PR}+\mathrm{SD})$ after 6 weeks of therapy $(p=0.02)$, whereas early ${ }^{18}$ F-FLT response ( $\geq 30 \%$ reduction) was 
found in six patients and was not predictive of non-progression $(p=0.39)$. Furthermore, patients with early ${ }^{18} \mathrm{~F}$ FDG response had significantly longer progression-free survival $(p=0.002)$ and overall survival $(p=0.04)$, whereas early ${ }^{18} \mathrm{~F}-\mathrm{FLT}$ response predicted significantly longer progression-free survival $(p=0.04)$ but not overall survival. Activating EGFR mutations were found in four patients, three of whom had PR and one SD. These patients showed a significant reduction in early ${ }^{18} \mathrm{~F}$-FDG uptake, whereas ${ }^{18}$ F-FLT uptake was reduced in three cases. Interestingly, almost half of the patients with an early ${ }^{18} \mathrm{~F}$ FDG response did not have detectable EGFR mutations but nevertheless had prolonged progression-free survival, indicating that ${ }^{18}$ F-FDG PET can identify, also, a subgroup of patients that may benefit from erlotinib treatment independently of EGFR mutational status. Imaging data from the same trial were analyzed using different methods to define SUV and volume of interest [50]. Patients with metabolic response on early ${ }^{18} \mathrm{~F}$-FDG PET and ${ }^{18} \mathrm{~F}$-FLT PET had a significantly prolonged progression-free interval regardless of the method used for SUV calculation. Furthermore, metabolically active volume measured either on early ${ }^{18}$ F-FLT scan or on late ${ }^{18}$ F-FDG scan was strongly associated with progression-free survival. In a retrospective analysis of data from the same study, absolute early and late residual ${ }^{18}$ F-FDG uptake, measured with different quantitative parameters, was also associated with nonprogression at 6 weeks [51]. By contrast, early and late residual ${ }^{18}$ F-FLT uptake was not associated with short-term outcome. Furthermore, low residual ${ }^{18}$ F-FDG and ${ }^{18}$ F-FLT uptake early or late in treatment was associated with improved progression-free survival.

In a multicenter trial ${ }^{18} \mathrm{~F}$-FDG PET and ${ }^{18}$ F-FLT PET responses were evaluated in second/third line NSCLC patients treated with erlotinib [52]. Baseline PET scans with both tracers were performed on separate days, and were repeated at day 14 and day 56 after the start of treatment in 51 patients. Tumor response was determined by CT performed at day 56 and four patients $(8 \%)$ showed partial response according to RECIST. PET partial metabolic response (PMR) was defined using EORTC criteria as a mean decrease in SUVmax (in $\leq 5$ lesions/patient) of at least $15 \%$. At day 14 and day 56, PMR with ${ }^{18}$ F-FDG was found in $26 \%$ and $16 \%$ of patients, respectively, whereas PMR with ${ }^{18}$ F-FLT was found in 18 and $16 \%$ of patients. Of the four patients with CT partial response, all showed PMR on both early and late ${ }^{18} \mathrm{~F}$-FDG scans, whereas three showed PMR on early ${ }^{18} \mathrm{~F}$-FLT scan and two on late ${ }^{18} \mathrm{~F}$ FLT scan. The percentage of patients showing PMR on early ${ }^{18} \mathrm{~F}$-FDG and ${ }^{18} \mathrm{~F}$-FLT scans was higher than that found on late scanning with the two tracers. PMR at day 14 and at day 56 , determined with ${ }^{18}$ F-FDG and ${ }^{18}$ F-FLT, was significantly associated with improved progression-free survival $(p \leq 0.02)$, whereas only ${ }^{18}$ F-FDG PMR at day 14 was significantly associated with improved overall survival $(p=0.03)$ even in the absence of subsequent RECIST response. Tumor tissues for mutational analysis were available in 35 patients and four had activating EGFR mutations, whereas seven had KRAS mutations. Three out of four EGFR-mutant tumors showed PMR on early ${ }^{18} \mathrm{~F}$ FDG scan whereas EGFR wild-type tumors showed PMR only in six out of 31 patients. Early reduction of ${ }^{18} \mathrm{~F}$-FDG uptake in EGFR-mutant tumors was higher (median $55 \%$ ) than that found in metabolic responding EGFR wild-type tumors (median $19.9 \%$ ). Tumors with KRAS mutations showed ${ }^{18}$ F-FDG PMR in one case at day 14 and in three patients at day 56 .

The results of the ${ }^{18} \mathrm{~F}$-FDG PET studies performed in this multicenter trial and in a second multicenter study were then grouped and analyzed to assess the predictive value of ${ }^{18} \mathrm{~F}$-FDG PET, clinical parameters and EGFR mutational status for survival duration by fitting accelerated failure time models [53]. Imaging data obtained at baseline and after 2 weeks of treatment with erlotinib were collected from a total of 125 NSCLC patients. The variables included in the model were performance status, sum of SUVmax of target lesions or total number of target lesions at baseline, percentage change in SUVmax at 2 weeks, appearance of new lesions at 2 weeks, and EGFR mutational status. New lesions on PET at 2 weeks, EGFR mutational status, performance status and baseline metabolic tumor burden were found to be independent and significant predictors of overall survival. Furthermore, a large (at least $35 \%$ ) reduction in SUVmax was strongly linked to EGFR mutational status and was predictive of survival only when EGFR mutational status was not considered.

In a prospective study 22 unselected patients with advanced NSCLC were evaluated by ${ }^{18}$ F-FDG PET/CT at baseline and after 2 weeks of therapy with erlotinib [54]. On the basis of PERCIST, metabolic response was defined as complete, partial ( $\geq 30 \%$ reduction in ${ }^{18} \mathrm{~F}$-FDG uptake), progressive metabolic disease ( $\geq 30 \%$ increase in ${ }^{18} \mathrm{~F}$-FDG uptake in a measurable target lesion or new lesions) or stable disease (not complete or partial metabolic response, no progression). Patients with progressive metabolic disease on early follow-up PET showed a significantly shorter time to progression (47 vs. 119 days, $p<0.001$ ) and overall survival ( 87 vs. 828 days, $p=0.01$ ) than patients classified as having stable metabolic disease or partial or complete metabolic response.

In another study 20 patients with lung adenocarcinoma were evaluated with ${ }^{18} \mathrm{~F}$-FDG PET/CT before and 2 days after the start of gefitinib treatment [55]. Metabolic response was evaluated using the European Organization for Research and Treatment of Cancer (EORTC) criteria 
and compared with morphological response evaluated by CT scan at 1 month post-treatment. After 2 days of gefitinib treatment, ten patients showed partial metabolic response, eight had stable metabolic disease, and two patients had metabolic progression. The percentage change in SUVmax at 2 days was significantly correlated with morphovolumetric reduction of tumors on CT scan at 1 month. EGFR mutational status was evaluated in 15 patients and of 12 patients with activating mutations, eight showed a metabolic response at 2 days and six showed a morphovolumetric response at 1 month. No metabolic or morphological response was observed in three patients with wild-type EGFR.

In a recent study, Scheffler et al. [56] reported the case of a patient with EGFR-mutant NSCLC treated sequentially with erlotinib and with an irreversible EGFR TKI and monitored by serial ${ }^{18}$ F-FLT PET studies. After an initial response to erlotinib that was associated with a reduction in ${ }^{18} \mathrm{~F}$-FLT uptake in tumor lesions and confirmed by CT, the patient showed clinical progression. ${ }^{18}$ F-FLT PET showed an increase in tracer uptake in tumor lesions, suggesting the development of resistance. The patient was then treated with afatinib and showed an improvement of clinical symptoms and a reduction in ${ }^{18}$ F-FLT uptake in targeted lesions. Unfortunately the response to afatinib was not durable and the treatment was discontinued.

\section{Molecular imaging with other tracers}

Besides ${ }^{18} \mathrm{~F}$-FDG and ${ }^{18} \mathrm{~F}$-FLT several radiolabeled agents have been developed for the non-invasive detection of EGFR expression, including antibodies, affibodies and small organic reversible and irreversible inhibitors [57]. An extensive review of these tracers is beyond the scope of the present article and we here limit ourselves to mentioning a few studies with tracers that proved able to distinguish EGFR TKI-sensitive from EGFR TKI-resistant tumors. Yeh et al. [58] developed ${ }^{18}$ F-PEG6-IPQA, a radiotracer with increased selectivity and irreversible binding to the active mutant L858R EGFR kinase. PET studies in animal models showed that ${ }^{18} \mathrm{~F}$-PEG6-IPQA is able to distinguish NSCLC xenografts bearing mutant L858R EGFR from those expressing wild-type EGFR. Furthermore, the expression of double-mutant L858R/T790M EGFR prevented the binding of ${ }^{18}$ F-PEG6-IPQA to the receptor both in vitro and in vivo.

The uptake and tumor kinetics of ${ }^{11} \mathrm{C}$-erlotinib were evaluated in ten patients with NSCLC, five with an EGFR exon 19 deletion and five without, using pharmacokinetic modeling and arterial blood sampling [59]. Patients with activating EGFR mutations showed higher ${ }^{11} \mathrm{C}$-erlotinib uptake than those without mutant EGFR.
Twenty-one patients with advanced NSCLC were studied with ${ }^{11} \mathrm{C}$-PD153035 and PET/CT at baseline, at 1-2 weeks and at 6 weeks after the start of therapy with erlotinib [60]. Uptake of ${ }^{11} \mathrm{C}-\mathrm{PD} 153035$ on the baseline scan significantly correlated with progression-free and overall survival. Patients with a higher SUVmax survived longer than those with a lower SUVmax. Uptake of ${ }^{11} \mathrm{C}$ PD153035 on follow-up scans was less predictive of outcome.

\section{Conclusions}

In conclusion, many studies indicate that ${ }^{18} \mathrm{~F}$-FDG may identify, early in the course of treatment, NSCLC patients who may or may not benefit from treatment with EGFR TKIs. Although ${ }^{18}$ F-FLT has been shown to detect effective EGFR inhibition and reversal of EGFR TKI resistance in animal models, it was less efficient than ${ }^{18} \mathrm{~F}$-FDG in predicting clinical outcome in NSCLC patients undergoing EGFR TKI treatment. There may be several reasons for this, including the lower tumor uptake of ${ }^{18} \mathrm{~F}-\mathrm{FLT}$, as compared to ${ }^{18} \mathrm{~F}-\mathrm{FDG}$ and the use of metabolic tumor response criteria that were designed essentially for ${ }^{18} \mathrm{~F}$ FDG studies. Furthermore, early reduction in ${ }^{18} \mathrm{~F}$-FLT uptake in response to EGFR TKIs indicates growth arrest of tumor cells that is not necessarily associated with a concomitant induction of apoptosis. Conversely, the reduction in ${ }^{18} \mathrm{~F}-\mathrm{FDG}$ uptake after treatment may reflect both inhibition of EGFR signaling and reduced cell viability. Therefore, ${ }^{18}$ F-FDG should be preferred to ${ }^{18}$ F-FLT for monitoring therapy with EGFR TKIs in NSCLC patients, even in those with unknown EGFR mutational status.

Due to the low rate of tumor response to EGFR TKIs in an unselected population of NSCLC patients and to the fact that EGFR-mutant NSCLC patients may also become refractory to treatment, the early detection of resistance is as important as the early identification of sensitivity. The existence of different therapeutic options and the availability of compounds that can be used to overcome acquired resistance to EGFR TKIs certainly open the way for designing rational strategies for the treatment of refractory patients. Although further clinical studies are needed, it is conceivable that ${ }^{18} \mathrm{~F}$-FLT may be preferable to ${ }^{18}$ F-FDG for detecting reversal of EGFR TKI resistance because changes in ${ }^{18} \mathrm{~F}$-FDG uptake in response to reversal agents may be uncoupled from changes in proliferation.

Although genetic profiling and mutational analysis are not fully integrated into daily oncology practice, it is to be hoped that newly diagnosed patients will be assigned to specific first-line therapy on the basis of molecular alterations found in tumor samples and then eventually 
monitored by functional imaging. NSCLC patients who initially respond to EGFR TKIs and then show disease progression may potentially benefit from treatment with irreversible EGFR TKIs or MET inhibitors. In such cases, the mechanism of resistance in each refractory patient should be identified. However, the biological detection of mechanisms of resistance in tumor samples is challenging for several reasons. Repeated biopsies are not usually performed in NSCLC patients whose tumors develop resistance. The methods currently available for the biological detection of T790M mutation and MET amplification are challenging and not sensitive enough. Furthermore, the two mechanisms of resistance are not mutually exclusive and may coexist in the same tumor or at different tumor sites. In this context, molecular imaging may provide tools for identifying refractory patients and for monitoring the effects of agents capable of overcoming EGFR TKI resistance in selected patients.

Acknowledgments This work was partly supported by Ministry of University and Research, MERIT-MEdical Research in ITaly (project No. RBNE08YFN3_008) and AIRC, Associazione Italiana per la Ricerca sul Cancro (project no.11756).

Conflict of interest F. Iommelli, V. De Rosa, R. Fonti, S. Del Vecchio declare no conflict of interest.

Human and animal studies This article does not contain any new studies with human or animal subjects performed by any of the authors.

\section{References}

1. Herbst RS, Maddox AM, Rothenberg ML, Small EJ, Rubin EH, Baselga J, Rojo F, Hong WK, Swaisland H, Averbuch SD, Ochs J, LoRusso PM (2002) Selective oral epidermal growth factor receptor tyrosine kinase inhibitor ZD1839 is generally well-tolerated and has activity in non-small-cell lung cancer and other solid tumors: results of a phase I trial. J Clin Oncol 20:3815-3825

2. Albanell J, Rojo F, Averbuch S, Feyereislova A, Mascaro JM, Herbst R, LoRusso P, Rischin D, Sauleda S, Gee J, Nicholson RI, Baselga J (2002) Pharmacodynamic studies of the epidermal growth factor receptor inhibitor ZD1839 in skin from cancer patients: histopathologic and molecular consequences of receptor inhibition. J Clin Oncol 20:110-124

3. Ranson M, Hammond LA, Ferry D, Kris M, Tullo A, Murray PI, Miller V, Averbuch S, Ochs J, Morris C, Feyereislova A, Swaisland H, Rowinsky EK (2002) ZD1839, a selective oral epidermal growth factor receptor-tyrosine kinase inhibitor, is well tolerated and active in patients with solid, malignant tumors: results of a phase I trial. J Clin Oncol 20:2240-2250

4. Nakagawa K, Tamura T, Negoro S, Kudoh S, Yamamoto N, Yamamoto N, Takeda K, Swaisland H, Nakatani I, Hirose M, Dong RP, Fukuoka M (2003) Phase I pharmacokinetic trial of the selective oral epidermal growth factor receptor tyrosine kinase inhibitor gefitinib ('Iressa', ZD1839) in Japanese patients with solid malignant tumors. Ann Oncol 14:922-930

5. Lynch TJ, Bell DW, Sordella R, Gurubhagavatula S, Okimoto RA, Brannigan BW, Harris PL, Haserlat SM, Supko JG, Haluska FG, Louis DN, Christiani DC, Settleman J, Haber DA (2004) Activating mutations in the epidermal growth factor receptor underlying responsiveness of non-small-cell lung cancer to gefitinib. N Engl $\mathrm{J}$ Med 350:2129-2139. doi:10.1056/NEJMoa040938

6. Paez JG, Janne PA, Lee JC, Tracy S, Greulich H, Gabriel S, Herman P, Kaye FJ, Lindeman N, Boggon TJ, Naoki K, Sasaki H, Fujii Y, Eck MJ, Sellers WR, Johnson BE, Meyerson M (2004) EGFR mutations in lung cancer: correlation with clinical response to gefitinib therapy. Science 304:1497-1500. doi:10. 1126/science.1099314

7. Pao W, Miller V, Zakowski M, Doherty J, Politi K, Sarkaria I, Singh B, Heelan R, Rusch V, Fulton L, Mardis E, Kupfer D, Wilson R, Kris M, Varmus H (2004) EGF receptor gene mutations are common in lung cancers from "never smokers" and are associated with sensitivity of tumors to gefitinib and erlotinib. Proc Natl Acad Sci USA 101:13306-13311. doi:10.1073/pnas. 0405220101

8. Gazdar AF (2009) Activating and resistance mutations of EGFR in non-small-cell lung cancer: role in clinical response to EGFR tyrosine kinase inhibitors. Oncogene 28(Suppl 1):S24-S31. doi:10.1038/onc. 2009.198

9. Inoue A, Suzuki T, Fukuhara T, Maemondo M, Kimura Y, Morikawa N, Watanabe H, Saijo Y, Nukiwa T (2006) Prospective phase II study of gefitinib for chemotherapy-naive patients with advanced non-small-cell lung cancer with epidermal growth factor receptor gene mutations. J Clin Oncol 24:3340-3346. doi:10.1200/JCO.2005.05.4692

10. Sequist LV, Martins RG, Spigel D, Grunberg SM, Spira A, Janne PA, Joshi VA, McCollum D, Evans TL, Muzikansky A, Kuhlmann GL, Han M, Goldberg JS, Settleman J, Iafrate AJ, Engelman JA, Haber DA, Johnson BE, Lynch TJ (2008) First-line gefitinib in patients with advanced non-small-cell lung cancer harboring somatic EGFR mutations. J Clin Oncol 26:2442-2449. doi:10.1200/JCO.2007.14.8494

11. Mok TS, Wu YL, Thongprasert S, Yang CH, Chu DT, Saijo N, Sunpaweravong P, Han B, Margono B, Ichinose Y, Nishiwaki Y, Ohe Y, Yang JJ, Chewaskulyong B, Jiang H, Duffield EL, Watkins CL, Armour AA, Fukuoka M (2009) Gefitinib or carboplatin-paclitaxel in pulmonary adenocarcinoma. N Engl J Med 361:947-957. doi:10.1056/NEJMoa0810699

12. Mitsudomi T, Morita S, Yatabe Y, Negoro S, Okamoto I, Tsurutani J, Seto T, Satouchi M, Tada H, Hirashima T, Asami K, Katakami N, Takada M, Yoshioka H, Shibata K, Kudoh S, Shimizu E, Saito H, Toyooka S, Nakagawa K, Fukuoka M, West Japan Oncology Group (2010) Gefitinib versus cisplatin plus docetaxel in patients with non-small-cell lung cancer harbouring mutations of the epidermal growth factor receptor (WJTOG3405): an open label, randomised phase 3 trial. Lancet Oncol 11:121-128. doi:10.1016/S1470-2045(09)70364-X

13. Rosell R, Moran T, Queralt C, Porta R, Cardenal F, Camps C, Majem M, Lopez-Vivanco G, Isla D, Provencio M, Insa A, Massuti B, Gonzalez-Larriba JL, Paz-Ares L, Bover I, Garcia-Campelo R, Moreno MA, Catot S, Rolfo C, Reguart N, Palmero R, Sanchez JM, Bastus R, Mayo C, Bertran-Alamillo J, Molina MA, Sanchez JJ, Taron M, Spanish Lung Cancer G (2009) Screening for epidermal growth factor receptor mutations in lung cancer. N Engl J Med 361:958-967. doi:10.1056/NEJMoa0904554

14. Sequist LV, Bell DW, Lynch TJ, Haber DA (2007) Molecular predictors of response to epidermal growth factor receptor antagonists in non-small-cell lung cancer. J Clin Oncol 25:587-595. doi:10.1200/JCO.2006.07.3585

15. Giaccone G, Rodriguez JA (2005) EGFR inhibitors: what have we learned from the treatment of lung cancer? Nat Clin Pract Oncol 2:554-561. doi:10.1038/ncponc0341

16. Scaltriti M, Baselga J (2006) The epidermal growth factor receptor pathway: a model for targeted therapy. Clin Cancer Res 12:5268-5272. doi:10.1158/1078-0432.CCR-05-1554 
17. Sharma SV, Bell DW, Settleman J, Haber DA (2007) Epidermal growth factor receptor mutations in lung cancer. Nat Rev Cancer 7:169-181. doi:10.1038/nrc2088

18. Pao W, Chmielecki J (2010) Rational, biologically based treatment of EGFR-mutant non-small-cell lung cancer. Nat Rev Cancer 10:760-774. doi:10.1038/nrc2947

19. Engelman JA, Janne PA (2008) Mechanisms of acquired resistance to epidermal growth factor receptor tyrosine kinase inhibitors in non-small cell lung cancer. Clin Cancer Res 14:2895-2899. doi:10.1158/1078-0432.CCR-07-2248

20. Faber AC, Corcoran RB, Ebi H, Sequist LV, Waltman BA, Chung E, Incio J, Digumarthy SR, Pollack SF, Song Y, Muzikansky A, Lifshits E, Roberge S, Coffman EJ, Benes CH, Gomez HL, Baselga J, Arteaga CL, Rivera MN, Dias-Santagata D, Jain RK, Engelman JA (2011) BIM expression in treatment-naive cancers predicts responsiveness to kinase inhibitors. Cancer Discov 1:352-365. doi:10.1158/2159-8290.CD-11-0106

21. Pratilas CA, Hanrahan AJ, Halilovic E, Persaud Y, Soh J, Chitale D, Shigematsu H, Yamamoto H, Sawai A, Janakiraman M, Taylor BS, Pao W, Toyooka S, Ladanyi M, Gazdar A, Rosen N, Solit DB (2008) Genetic predictors of MEK dependence in nonsmall cell lung cancer. Cancer Res 68:9375-9383. doi:10.1158/ 0008-5472.CAN-08-2223

22. Soda M, Choi YL, Enomoto M, Takada S, Yamashita Y, Ishikawa S, Fujiwara S, Watanabe $H$, Kurashina $K$, Hatanaka $H$, Bando M, Ohno S, Ishikawa Y, Aburatani H, Niki T, Sohara Y, Sugiyama Y, Mano H (2007) Identification of the transforming EML4-ALK fusion gene in non-small-cell lung cancer. Nature 448:561-566. doi:10.1038/nature05945

23. Rikova K, Guo A, Zeng Q, Possemato A, Yu J, Haack H, Nardone J, Lee K, Reeves C, Li Y, Hu Y, Tan Z, Stokes M, Sullivan L, Mitchell J, Wetzel R, Macneill J, Ren JM, Yuan J, Bakalarski CE, Villen J, Kornhauser JM, Smith B, Li D, Zhou X, Gygi SP, Gu TL, Polakiewicz RD, Rush J, Comb MJ (2007) Global survey of phosphotyrosine signaling identifies oncogenic kinases in lung cancer. Cell 131:1190-1203. doi:10.1016/j.cell.2007.11.025

24. Pao W, Girard N (2011) New driver mutations in non-small-cell lung cancer. Lancet Oncol 12:175-180. doi:10.1016/S14702045(10)70087-5

25. Gridelli C, Solange P, Sgambato A, Casaluce F, Adjei AA, Ciardiello F (2013) ALK inhibitors in the treatment of advanced NSCLC. Cancer Treat Rev. doi:10.1016/j.ctrv.2013.07.002

26. Kawano O, Sasaki H, Endo K, Suzuki E, Haneda H, Yukiue H, Kobayashi Y, Yano M, Fujii Y (2006) PIK3CA mutation status in Japanese lung cancer patients. Lung Cancer 54:209-215. doi:10. 1016/j.lungcan.2006.07.006

27. Sos ML, Koker M, Weir BA, Heynck S, Rabinovsky R, Zander T, Seeger JM, Weiss J, Fischer F, Frommolt P, Michel K, Peifer M, Mermel C, Girard L, Peyton M, Gazdar AF, Minna JD, Garraway LA, Kashkar H, Pao W, Meyerson M, Thomas RK (2009) PTEN loss contributes to erlotinib resistance in EGFR-mutant lung cancer by activation of Akt and EGFR. Cancer Res 69:3256-3261. doi:10.1158/0008-5472.CAN-08-4055

28. Riely GJ, Kris MG, Zhao B, Akhurst T, Milton DT, Moore E, Tyson L, Pao W, Rizvi NA, Schwartz LH, Miller VA (2007) Prospective assessment of discontinuation and reinitiation of erlotinib or gefitinib in patients with acquired resistance to erlotinib or gefitinib followed by the addition of everolimus. Clin Cancer Res 13:5150-5155. doi:10.1158/1078-0432.CCR-070560

29. Sequist LV, Waltman BA, Dias-Santagata D, Digumarthy S, Turke AB, Fidias P, Bergethon K, Shaw AT, Gettinger S, Cosper AK, Akhavanfard S, Heist RS, Temel J, Christensen JG, Wain JC, Lynch TJ, Vernovsky K, Mark EJ, Lanuti M, Iafrate AJ, Mino-Kenudson M, Engelman JA (2011) Genotypic and histological evolution of lung cancers acquiring resistance to EGFR inhibitors. Sci Transl Med 3:75ra26. doi:10.1126/scitranslmed. 3002003

30. Blumenschein GR Jr, Mills GB, Gonzalez-Angulo AM (2012) Targeting the hepatocyte growth factor-cMET axis in cancer therapy. J Clin Oncol 30:3287-3296. doi:10.1200/JCO.2011.40. 3774

31. Pao W, Kris MG, Iafrate AJ, Ladanyi M, Janne PA, Wistuba II, Miake-Lye R, Herbst RS, Carbone DP, Johnson BE, Lynch TJ (2009) Integration of molecular profiling into the lung cancer clinic. Clin Cancer Res 15:5317-5322. doi:10.1158/1078-0432. CCR-09-0913

32. Kwak EL, Sordella R, Bell DW, Godin-Heymann N, Okimoto RA, Brannigan BW, Harris PL, Driscoll DR, Fidias P, Lynch TJ, Rabindran SK, McGinnis JP, Wissner A, Sharma SV, Isselbacher KJ, Settleman J, Haber DA (2005) Irreversible inhibitors of the EGF receptor may circumvent acquired resistance to gefitinib. Proc Natl Acad Sci USA 102:7665-7670. doi:10.1073/pnas. 0502860102

33. Engelman JA, Zejnullahu K, Gale CM, Lifshits E, Gonzales AJ, Shimamura T, Zhao F, Vincent PW, Naumov GN, Bradner JE, Althaus IW, Gandhi L, Shapiro GI, Nelson JM, Heymach JV, Meyerson M, Wong KK, Janne PA (2007) PF00299804, an irreversible pan-ERBB inhibitor, is effective in lung cancer models with EGFR and ERBB2 mutations that are resistant to gefitinib. Cancer Res 67:11924-11932. doi:10.1158/0008-5472. CAN-07-1885

34. Zhou W, Ercan D, Chen L, Yun CH, Li D, Capelletti M, Cortot $\mathrm{AB}$, Chirieac L, Iacob RE, Padera R, Engen JR, Wong KK, Eck MJ, Gray NS, Janne PA (2009) Novel mutant-selective EGFR kinase inhibitors against EGFR T790M. Nature 462:1070-1074. doi:10.1038/nature08622

35. Tehrani OS, Shields AF (2013) PET imaging of proliferation with pyrimidines. J Nucl Med 54:903-912. doi:10.2967/jnumed.112. 112201

36. Buck AK, Schirrmeister H, Hetzel M, Von Der Heide M, Halter G, Glatting G, Mattfeldt T, Liewald F, Reske SN, Neumaier B (2002) 3-deoxy-3- $\left[{ }^{18} \mathrm{~F}\right]$ fluorothymidine-positron emission tomography for noninvasive assessment of proliferation in pulmonary nodules. Cancer Res 62:3331-3334

37. Vesselle H, Grierson J, Muzi M, Pugsley JM, Schmidt RA, Rabinowitz P, Peterson LM, Vallieres E, Wood DE (2002) In vivo validation of $3^{\prime}$ deoxy- $3^{\prime}-\left[{ }^{18} \mathrm{~F}\right]$ fluorothymidine $\left(\left[{ }^{18} \mathrm{~F}\right] \mathrm{FLT}\right)$ as a proliferation imaging tracer in humans: correlation of $\left[{ }^{18} \mathrm{~F}\right] \mathrm{FLT}$ uptake by positron emission tomography with Ki-67 immunohistochemistry and flow cytometry in human lung tumors. Clin Cancer Res 8:3315-3323

38. Van de Wiele C, Kruse V, Smeets P, Sathekge M, Maes A (2013) Predictive and prognostic value of metabolic tumour volume and total lesion glycolysis in solid tumours. Eur J Nucl Med Mol Imaging 40:290-301. doi:10.1007/s00259-012-2280-Z

39. Bille A, Okiror L, Skanjeti A, Errico L, Arena V, Penna D, Ardissone F, Pelosi E (2013) The prognostic significance of maximum standardized uptake value of primary tumor in surgically treated non-small-cell lung cancer patients: analysis of 413 cases. Clin Lung Cancer 14:149-156. doi:10.1016/j.cllc.2012.04.007

40. Huang W, Zhou T, Ma L, Sun H, Gong H, Wang J, Yu J, Li B (2011) Standard uptake value and metabolic tumor volume of ${ }^{18}$ F-FDG PET/CT predict short-term outcome early in the course of chemoradiotherapy in advanced non-small cell lung cancer. Eur J Nucl Med Mol Imaging 38:1628-1635. doi:10.1007/ s00259-011-1838-5

41. Fonti R, Larobina M, Del Vecchio S, De Luca S, Fabbricini R, Catalano L, Pane F, Salvatore M, Pace L (2012) Metabolic tumor volume assessed by ${ }^{18}$ F-FDG PET/CT for the prediction of outcome in patients with multiple myeloma. J Nucl Med 53:1829-1835. doi:10.2967/jnumed.112.106500 
42. Cairns RA, Harris IS, Mak TW (2011) Regulation of cancer cell metabolism. Nat Rev Cancer 11:85-95. doi:10.1038/nrc2981

43. Su H, Bodenstein C, Dumont RA, Seimbille Y, Dubinett S, Phelps ME, Herschman H, Czernin J, Weber W (2006) Monitoring tumor glucose utilization by positron emission tomography for the prediction of treatment response to epidermal growth factor receptor kinase inhibitors. Clin Cancer Res 12:5659-5667. doi:10.1158/1078-0432.CCR-06-0368

44. Sunaga N, Oriuchi N, Kaira K, Yanagitani N, Tomizawa Y, Hisada T, Ishizuka T, Endo K, Mori M (2008) Usefulness of FDG-PET for early prediction of the response to gefitinib in nonsmall cell lung cancer. Lung Cancer 59:203-210. doi:10.1016/j. lungcan.2007.08.012

45. Aukema TS, Kappers I, Olmos RA, Codrington HE, van Tinteren H, van Pel R, Klomp HM, Group NELS (2010) Is ${ }^{18}$ F-FDG PET/ CT useful for the early prediction of histopathologic response to neoadjuvant erlotinib in patients with non-small cell lung cancer? J Nucl Med 51:1344-1348. doi:10.2967/jnumed.110.076224

46. Ullrich RT, Zander T, Neumaier B, Koker M, Shimamura T, Waerzeggers Y, Borgman CL, Tawadros S, Li H, Sos ML, Backes H, Shapiro GI, Wolf J, Jacobs AH, Thomas RK, Winkeler A (2008) Early detection of erlotinib treatment response in NSCLC by $3^{\prime}$-deoxy- $3^{\prime}-\left[{ }^{18} \mathrm{~F}\right]$-fluoro-L-thymidine $\left(\left[{ }^{18} \mathrm{~F}\right] \mathrm{FLT}\right)$ positron emission tomography (PET). PLoS One 3:e3908. doi:10. 1371/journal.pone.0003908

47. Zannetti A, Iommelli F, Speranza A, Salvatore M, Del Vecchio S (2012) $3^{\prime}$-deoxy $-3^{\prime}{ }_{-}{ }^{18}$ F-fluorothymidine PET/CT to guide therapy with epidermal growth factor receptor antagonists and Bcl-xL inhibitors in non-small cell lung cancer. J Nucl Med 53:443-450. doi:10.2967/jnumed.111.096503

48. Sohn HJ, Yang YJ, Ryu JS, Oh SJ, Im KC, Moon DH, Lee DH, Suh C, Lee JS, Kim SW (2008) $\left[{ }^{18}\right.$ F]Fluorothymidine positron emission tomography before and 7 days after gefitinib treatment predicts response in patients with advanced adenocarcinoma of the lung. Clin Cancer Res 14:7423-7429. doi:10.1158/10780432.CCR-08-0312

49. Zander T, Scheffler M, Nogova L, Kobe C, Engel-Riedel W, Hellmich M, Papachristou I, Toepelt K, Draube A, Heukamp L, Buettner R, Ko YD, Ullrich RT, Smit E, Boellaard R, Lammertsma AA, Hallek M, Jacobs AH, Schlesinger A, Schulte K, Querings S, Stoelben E, Neumaier B, Thomas RK, Dietlein M, Wolf J (2011) Early prediction of nonprogression in advanced non-small-cell lung cancer treated with erlotinib by using $\left[{ }^{18} \mathrm{~F}\right]$ fluorodeoxyglucose and $\left[{ }^{18} \mathrm{~F}\right]$ fluorothymidine positron emission tomography. J Clin Oncol 29:1701-1708. doi:10.1200/ JCO.2010.32.4939

50. Kahraman D, Scheffler M, Zander T, Nogova L, Lammertsma AA, Boellaard R, Neumaier B, Ullrich RT, Holstein A, Dietlein M, Wolf J, Kobe C (2011) Quantitative analysis of response to treatment with erlotinib in advanced non-small cell lung cancer using ${ }^{18} \mathrm{~F}$-FDG and $3^{\prime}$-deoxy- $3^{\prime}{ }_{-}^{18} \mathrm{~F}$-fluorothymidine PET. J Nucl Med 52:1871-1877. doi:10.2967/jnumed.111.094458

51. Kobe C, Scheffler M, Holstein A, Zander T, Nogova L, Lammertsma AA, Boellaard R, Neumaier B, Ullrich RT, Dietlein M, Wolf J, Kahraman D (2012) Predictive value of early and late residual ${ }^{18} \mathrm{~F}$-fluorodeoxyglucose and ${ }^{18} \mathrm{~F}$-fluorothymidine uptake using different SUV measurements in patients with non-smallcell lung cancer treated with erlotinib. Eur J Nucl Med Mol Imaging 39:1117-1127. doi:10.1007/s00259-012-2118-8

52. Mileshkin L, Hicks RJ, Hughes BG, Mitchell PL, Charu V, Gitlitz BJ, Macfarlane D, Solomon B, Amler LC, Yu W, Pirzkall A, Fine BM (2011) Changes in ${ }^{18} \mathrm{~F}$-fluorodeoxyglucose and ${ }^{18} \mathrm{~F}$ fluorodeoxythymidine positron emission tomography imaging in patients with non-small cell lung cancer treated with erlotinib. Clin Cancer Res 17:3304-3315. doi:10.1158/1078-0432.CCR-102763

53. Bengtsson T, Hicks RJ, Peterson A, Port RE (2012) ${ }^{18}$ F-FDG PET as a surrogate biomarker in non-small cell lung cancer treated with erlotinib: newly identified lesions are more informative than standardized uptake value. J Nucl Med 53:530-537. doi:10.2967/jnumed.111.092544

54. Benz MR, Herrmann K, Walter F, Garon EB, Reckamp KL, Figlin R, Phelps ME, Weber WA, Czernin J, Allen-Auerbach MS (2011) ${ }^{18}$ F-FDG PET/CT for monitoring treatment responses to the epidermal growth factor receptor inhibitor erlotinib. J Nucl Med 52:1684-1689. doi:10.2967/jnumed.111.095257

55. Takahashi R, Hirata H, Tachibana I, Shimosegawa E, Inoue A, Nagatomo I, Takeda Y, Kida H, Goya S, Kijima T, Yoshida M, Kumagai T, Kumanogoh A, Okumura M, Hatazawa J, Kawase I (2012) Early $\left[{ }^{18} \mathrm{~F}\right]$ fluorodeoxyglucose positron emission tomography at two days of gefitinib treatment predicts clinical outcome in patients with adenocarcinoma of the lung. Clin Cancer Res 18:220-228. doi:10.1158/1078-0432.CCR-11-0868

56. Scheffler M, Kobe C, Zander T, Nogova L, Kahraman D, Thomas R, Neumaier B, Dietlein M, Wolf J (2012) Monitoring reversible and irreversible EGFR inhibition with erlotinib and afatinib in a patient with EGFR-mutated non-small cell lung cancer (NSCLC) using sequential $\left[{ }^{18} \mathrm{~F}\right]$ fluorothymidine (FLT-)PET. Lung Cancer 77:617-620. doi:10.1016/j.lungcan.2012.05.110

57. Mishani E, Hagooly A (2009) Strategies for molecular imaging of epidermal growth factor receptor tyrosine kinase in cancer. J Nucl Med 50:1199-1202. doi:10.2967/jnumed.109.062117

58. Yeh HH, Ogawa K, Balatoni J, Mukhapadhyay U, Pal A, Gonzalez-Lepera C, Shavrin A, Soghomonyan S, Flores L 2nd, Young D, Volgin AY, Najjar AM, Krasnykh V, Tong W, Alauddin MM, Gelovani JG (2011) Molecular imaging of active mutant L858R EGF receptor (EGFR) kinase-expressing nonsmall cell lung carcinomas using PET/CT. Proc Natl Acad Sci USA 108:1603-1608. doi:10.1073/pnas.1010744108

59. Bahce I, Smit EF, Lubberink M, van der Veldt AA, Yaqub M, Windhorst AD, Schuit RC, Thunnissen E, Heideman DA, Postmus PE, Lammertsma AA, Hendrikse NH (2013) Development of $\left[{ }^{11} \mathrm{C}\right]$ erlotinib positron emission tomography for in vivo evaluation of EGF receptor mutational status. Clin Cancer Res 19:183-193. doi:10.1158/1078-0432.CCR-12-0289

60. Meng X, Loo BW Jr, Ma L, Murphy JD, Sun X, Yu J (2011) Molecular imaging with ${ }^{11} \mathrm{C}$-PD153035 PET/CT predicts survival in non-small cell lung cancer treated with EGFR-TKI: a pilot study. J Nucl Med 52:1573-1579. doi:10.2967/jnumed.111. 092874 